\title{
Improving Text Comprehension: Scaffolding Adolescents into Strategic Reading
}

\author{
Teresa A. Ukrainetz, Ph.D. ${ }^{1}$
}

\begin{abstract}
Understanding and learning from academic texts involves purposeful, strategic reading. Adolescent readers, particularly poor readers, benefit from explicit instruction in text comprehension strategies, such as text preview, summarization, and comprehension monitoring, as part of a comprehensive reading program. However, strategies are difficult to teach within subject area lessons where content instruction must take primacy. Speech-language pathologists (SLPs) have the expertise and service delivery options to support middle and high school students in learning to use comprehension strategies in their academic reading and learning. This article presents the research evidence on what strategies to teach and how best to teach them, including the use of explicit instruction, spoken interactions around text, cognitive modeling, peer learning, classroom connections, and disciplinary literacy. The article focuses on how to move comprehension strategies from being teaching tools of the SLP to becoming learning tools of the student. SLPs can provide the instruction and support needed for students to learn and apply of this important component of academic reading.
\end{abstract}

KEYWORDS: Reading comprehension, text comprehension, strategies, speech-language pathologist, language intervention, adolescent

Learning Outcomes: As a result of this activity, the reader will be able to (1) identify simple comprehension strategies that can be effectively taught to middle and high school students who are poor readers; (2) explain how to scaffold use of strategies from instructor control in structured tasks to student control in academic learning tasks.

\footnotetext{
${ }^{1}$ Division of Communication Disorders, University of Wyoming, Laramie, Wyoming.

Address for correspondence: Teresa A. Ukrainetz, Ph.D., Division of Communication Disorders, Department 3311, University of Wyoming, 1000 E. University Ave., Laramie, WY 82071-3311 (e-mail: tukraine@uwyo.edu).
}

\footnotetext{
Spotlight on Adolescent and Adult Language and Literacy; Guest Editor, Karen A. Fallon, Ph.D., CCC-SLP.

Semin Speech Lang 2015;36:17-30. Copyright (C) 2015 by Thieme Medical Publishers, Inc., 333 Seventh Avenue, New York, NY 10001, USA. Tel: +1(212) 584-4662. DOI: http://dx.doi.org/10.1055/s-0034-1396443. ISSN 0734-0478.
} 
Instruction in text comprehension strategies, such as text preview, summarization, and comprehension monitoring, is a critical part of a comprehensive reading program. Speechlanguage pathologists (SLPs) are well situated to provide the explicit, systematic instruction needed to move students from passive responders to active, purposeful learners who can use strategies to improve their comprehension and learning. This article presents effective instructional practices for strategy instruction as part of a comprehensive approach to improving adolescent reading and learning of academic texts.

\section{EFFECTIVE COMPREHENSION INSTRUCTION}

In 2000, the National Reading Panel (NRP) reviewed the research evidence across areas of reading instruction. ${ }^{1}$ For the area of reading comprehension, the review of the controlled research evidence published between 1980 and 1998 resulted in 205 studies of students in third to eighth grade across a range of reading levels. The review revealed seven teaching procedures that showed a firm scientific basis: cooperative learning, answering teacher questions, graphic organizers, story structure analysis, comprehension monitoring, question generation, and summarization. NRP determined that use of multiple procedures was more effective than use of any single strategy, but there was insufficient evidence to determine the most effective amounts or combinations of instructional procedures.

A more recent guide to best practices for reading comprehension instruction by Kamil and colleagues systematically examined the research evidence and developed specific instructional recommendations for students in eighth grade and above. ${ }^{2}$ The report organized the instructional recommendations into four attributes of effective instruction: (1) explicit vocabulary instruction, (2) direct and explicit comprehension strategy instruction, (3) opportunities for extended discussion of text meaning and interpretation, and (4) increasing student motivation and engagement in literacy learning. Kamil et al found strong research evidence for the first two features, which meant well-designed controlled trials with no contradictory evidence. The latter two had moderate levels of evidence, which meant multiple studies and no contradictory evidence, but the studies had design features that limited generalization, such as small sample size, or limited causation, such as nonequivalent comparison groups. Kamil et al recommended that these four instructional attributes be present not only within language arts classes, but also in other subject areas, such as history and science. The report addressed structural and behavioral obstacles to implementing these features within subject area instruction and suggested ways for teachers to deal with these challenges.

In addition to these four instructional features, Kamil et al recognized a fifth instructional attribute aimed at struggling readers. ${ }^{2}$ The authors reported strong research evidence for provision of intensive, explicit, individualized interventions by trained specialists. Substantial improvement could be obtained in the reading performance of struggling readers if they are identified, their strengths and weaknesses are systematically assessed, and intensive interventions are provided that are crafted to their particular needs. Kamil et al discussed disconnects between subject area teachers and learning specialists, and the researchers emphasized the need to forge stronger links between regular and special education settings.

These recommendations open an avenue for the involvement of SLPs in text comprehension instruction. Special educators such as resource teachers and SLPs provide the individualized instruction needed to support struggling students. Although these two specialists have many shared areas of expertise and service delivery, there are also differences that can contribute to a greater whole. ${ }^{3}$ Like subject area teachers, resource teachers have the curricular knowledge and daily extended contact with students to give them access to rich vocabulary learning experiences and extended meaningmaking discussions about literature and informational texts. In contrast, SLPs have the curricular freedom, underlying skills focus, problem-solving orientation, and treatment expertise to provide the explicit, individualized, scaffolded instruction needed to teach students to use comprehension strategies. SLPs can connect with the classroom to help students apply these learning tools to classroom texts. 
Students who are more in control of their own learning will have greater motivation and engagement, contributing to a self-sustaining path of improvement. Thus, SLPs and other educators can work together to provide comprehensive, effective reading comprehension instruction for struggling students.

\section{WRITTEN AND SPOKEN TEXT COMPREHENSION}

Text refers to the main body of printed or written matter on a page. ${ }^{4}$ Text can be prose, consisting of sentences connected into paragraphs and passages, such as in books, essays, and reports, or document, consisting of noncontinuous words and phrases, such as in forms, Web sites, and pamphlets. ${ }^{5}$ Text may even include spoken words, diagrams, or photographs. ${ }^{6}$

Text comprehension is an open-ended arena involving knowledge and skills in vocabulary, grammar, discourse, attention, memory, concepts, and pragmatics. Understanding can be a simple, literal recall or a nuanced synthesis of inference, knowledge, and evaluation. Academic comprehension involves both understanding what is read and learning from what is understood. Text comprehension is affected by the skills and attitudes brought by the reader, the form and content of the material, and the purpose and conditions of the activity. ${ }^{7}$

Reading comprehension has been defined as "the process of simultaneously extracting and constructing meaning through interaction and involvement with written language." (7,p.xiii) This definition emphasizes the active nature of comprehension and goes beyond silently reading a printed page to meaning making through spoken interactions around print. Students can listen to others read, have literate discussions, talk about written-style sentences and discourse, and refer to texts to find information. Within these interactions, students can build on each other's contributions and scaffolded support from the SLP.

\section{READING COMPREHENSION STRATEGIES}

Multiple reviews of the research have supported increasing students' awareness and optimiza- tion of their mental processes to improve comprehension and learning of academic texts across a range of reading levels and learning abilities. ${ }^{1,2,7-10}$ This awareness and optimization of mental processes is obtained through comprehension strategies. Two recent systematic reviews of comprehension intervention studies for students with learning disabilities found consistent sizeable improvements from comprehension intervention that consisted largely of teaching reading strategies. ${ }^{11,12}$ Not surprisingly, Swanson et al reported that older students benefitted more from this metacognitive approach than did students from third to sixth grade. ${ }^{12}$

The word strategy is used in many ways, but fundamentally, strategies are heuristics: shortterm, general problem-solving procedures that highlight information and guide attentional focus. ${ }^{10}$ Prereading strategies include thinking about what is already known about the topic, predicting the text content, and identifying a plan for reading. During-reading strategies include maintaining the reading purpose, noting important information, paraphrasing ideas, integrating new with known information, and staying alert to lapses in understanding. Afterreading strategies involve recalling the main or important ideas, reviewing what has been learned, and rereading to fill in comprehension gaps. SLPs can enhance their own awareness of comprehension strategies by finding a text that is difficult for them, assigning themselves a reading objective, and reflecting on their own cognitive processes before, during, and after purposeful reading.

Strategies are generally considered to involve conscious application of mental operations. ${ }^{13}$ Strategies contrast with skills, which are applied "unconsciously, for many reasons including expertise, repeated practice, compliance with directions, luck, and naive use."(13,p.611) Skills and strategies can be viewed as two sides of a coin: skills become strategies when they are raised to conscious attention and strategies become skills when they sink to the subconscious level. ${ }^{14,15}$ For example, when reading for pleasure, skilled readers can enjoy a book with no awareness of the act of reading. However, they move into a strategic, deliberate mode when they encounter and puzzle over an opaque passage or an unfamiliar 
multisyllabic word. Learning new skills, modifying old skills, or applying skills in challenging conditions are all ways that skills surface as conscious strategies. Skillful execution of an activity is done easily, with little mental energy, whereas strategies take work and strategic operators tire quickly. Poor readers must frequently engage in this energy-consuming style of reading, contributing to the loss of motivation and effort flag for older students with histories of struggle and unsatisfactory results.

Reading strategies are generalizable and adaptable across reading situations. Readers select from these strategies to accomplish their goals within specific activities. Skimming, careful reading, memorizing, seeking the main idea, or editing all involve different strategies. Rather than telling students to "learn it all," teachers can point out what is more and less important in a text and show how to strategically read difficult texts by looking for key sections and critical elements. Students are sometimes surprised to learn that strategic skimming is not a surreptitious shortcut but rather a valid approach to reading.

\section{SELECTING READING STRATEGIES TO TEACH}

NRP identified three types of reading strategies that show a firm scientific basis: comprehension monitoring (readers being aware of their own understanding of the text), question generation (readers asking themselves questions about the text), and summarization (readers integrating ideas from the text). ${ }^{1}$ Kamil et al reiterated the NRP findings on effective reading strategies and added paraphrasing (readers restating a sentence in their own words) as another effective strategy. ${ }^{2}$ In addition, teaching wordlearning strategies was an important part of vocabulary instruction. When students come across unfamiliar words or unfamiliar uses of known words, they need to know how to help themselves using context cues and reference skills.

Two earlier systematic reviews reported that helpful strategies tend to be specific prompts with set wording about text ideas (e.g., "What is the main idea of this paragraph? What is the difference between this idea and the preceding idea?") and text structure (e.g., "What was the problem in this story? Can you tell where in the story the problem was resolved?"). ${ }^{9,10}$ Less beneficial is having students generate questions based on their perceptions of what is important or what they think that a teacher might ask. Mason found, for oral summarization of expository passages, that teaching fifth graders a set of prompts to identify the author's purpose, the reader's purpose, and the main idea, along with noticing their reading speed and remembering to reread parts, was superior to a procedure called reciprocal questioning, which involved teaching students to generate their own questions and predictions crafted to the content of each text they read. ${ }^{16}$

Two commonly taught strategies are asking clarification questions about unclear text and making predictions about upcoming text. However, these may not be very helpful strategies. Rosenshine and Meister reported that, with informational texts, middle school students can learn to ask questions about material that is unclear to them, but they have trouble finding clarifying answers in the texts. ${ }^{10}$ Predicting upcoming information is also problematic because topics often shift abruptly between paragraphs and sections.

Although there are more and less helpful strategies, the critical aspect is not so much which specific strategies are taught, but rather that multiple strategies are introduced, that the process engenders the active participation of students in their own comprehension, and that there is sufficient scaffolding to move the students toward self-regulated use. ${ }^{2}$ Strategies should contribute to students approaching their texts with mindful engagement. Gersten et al described strategies as crude approximations of what expert readers occasionally engage in. ${ }^{8}$ What matters most is that students get into the habit of asking themselves, "What did that part say?" and responding with, "I am not sure what it said. I better reread that part."

\section{HOW TO TEACH COMPREHENSION STRATEGIES}

There are a variety of effective teaching procedures and supports, ${ }^{7-10,17}$ all of which fit well with SLP expertise and practices. Several important components of instruction have been 
identified across the research: (1) explicit teacher modeling, (2) practice with feedback, (3) adjustment of support to the learner level, and (4) having students maintain a mindful engagement with the purposes of the reading. A review of intervention research on students with learning disabilities found that of 20 instructional components, just three explained almost all the common variance in outcomes: (1) controlling task difficulty, (2) using small interactive groups, and (3) having students use a specified language or format for strategy questions. ${ }^{18}$

The instructor is a critical part of effective strategy instruction. Traditionally, the teacher is a task director who requires, supervises, and evaluates recitations, content recall, and writing activities. ${ }^{19}$ Improved comprehension outcomes have been obtained when teachers are interactive, asking questions about text structure, linking text to background knowledge, and engaging students in asking their own questions. Cognitive modeling of strategies involves demonstrating thinking processes during purposeful reading so that students see the when, why, and how, not just what of reading. ${ }^{2,19,20}$ Effective modeling practices include: (1) before students begin to read, demonstrating how to read for a particular purpose; (2) during the reading, demonstrating at designated stopping points or when students have difficulties; and (3) after the reading, reviewing performance and demonstrating more effective use of the strategies. For SLPs, such interactive modeling and learning through talking are integral to language treatment.

The importance of introducing strategies separately from new content is illustrated by McKeown and colleagues, ${ }^{21}$ who compared the effects of content-focused instruction to a strategy-focused condition and a scripted basal text condition for six classrooms of fifth graders over a school year. In the content-focused instruction, students read a passage aloud and discuss what the author is trying to communicate at key points, such as when a major character is introduced, an important event has occurred, or a confusing statement is made. Year-end results showed sizeable improvements with no significant differences across the three approaches for several of the comprehension measures, including comprehension monitor- ing and recognition of better summaries and inferences. However, for familiar and new text knowledge probes, responses were better for the content condition.

McKeown et al noted that, in different ways, all three approaches encouraged active comprehension and mental discourse templates but that the content condition allowed students to have a single focus on concept acquisition. ${ }^{21}$ For the strategies condition, the focus was split between strategies and content: students were thinking about what makes a good question or how to construct a summary instead of responding to simple, integrative content questions like "What's going on?" McKeown et al suggested that rather than teach content and strategies concurrently, strategies should be taught using short texts separate from the main lesson, then introduced into the content lesson as natural opportunities occur. An SLP can provide this kind of focused learning and practice for strategy uses identified collaboratively with teachers. After students have some control over the strategies, the SLP can work with the teachers to introduce strategy use within content lessons.

Small groups provide a more natural context than teacher-student exchanges for students to "think aloud" about their own reading strategies and comprehension processes. ${ }^{1,8} \mathrm{Stu}-$ dents benefit from talking with each other about what they are reading and from embedding strategic questioning into these conversations. Students can take turns being teachers. With SLP assistance, "student-teachers" can lead the process, asking comprehension questions of other students, helping them find the answers, and evaluating their answers, in a process called reciprocal teaching. ${ }^{22}$ Again, SLPs are well suited to this kind of instruction with their typical small-group intervention through scaffolded spoken interactions and freedom from immediate curricular demands.

\section{WHOSE STRATEGY IS IT?}

A confusing aspect of strategy instruction is that the word strategy is used in two quite different ways in the literature: as a teaching strategy and as a learning strategy. Even NRP and Kamil et al group the two together as "instruction strategies" and do not distinguish who is using the 
strategy. ${ }^{1,2}$ Shanahan et al, in a best practices guide for primary-grade comprehension instruction, note that many intervention studies for younger students do not systematically scaffold students toward independence. ${ }^{23}$ The intervention research for older students typically does include some guided and independent practice, but the instruction and the outcome measurement rarely address self-directed use in the classroom.

Effective comprehension teaching procedures include posing questions to students after they read a story, placing students in cooperative learning groups, or leading students in creating graphical organizers of main ideas and details. ${ }^{1,7}$ These teaching strategies are used to improve students' vocabulary, sentence structure, discourse structure, or content knowledge, all of which contribute to better reading comprehension. Students may even notice (or be told) that these are useful procedures, but they are not directly taught and given practice using them as their own learning tools. In contrast, as a learning tool, students use simple cognitive acts to improve their own comprehension before, during, and after reading or listening to academic texts. Students are explicitly and systematically taught to ask themselves a question, identify a main idea, or repair their comprehension as needed in their own reading. In contrast to use as a teaching strategy, use as a learning strategy requires, in addition to progress data on whether text comprehension improves, data that suggest the students are using their new strategies with increasing independence and effectiveness to obtain the improved text comprehension.

The issue of taking ownership occurs even when the student is taught to use the strategy as a learning tool. Many students stop using their learned strategies as soon as the requirements and reminders are removed. ${ }^{8}$ For example, Chan and Cole taught 11-year-olds with reading disabilities to ask themselves and a robot content questions, to underline interesting words with a fluorescent pen, and to explain to the robot why these words were interesting. ${ }^{24}$ After only four sessions, the students improved their comprehension and recall of stories compared with a control condition in which the students simply reread the story to the robot in case the robot missed parts the first time. However, one day after the training, when given two stories with no directions for how to read, none of the students used the explaining and question-generating strategies. Two-thirds of the students used the underlining strategy to some degree without direction. What really matters is continued use, suggesting that simple, appealing strategies like fluorescent underlining may be best.

The control and awareness needed for strategic reading is challenging for many students. In addition to specific strategy instruction, students with learning disabilities often benefit from a broader focus on self-regulation and executive function., ${ }^{8,25} \mathrm{~A}$ program that explicitly and systematically does this is selfregulated strategy development. ${ }^{26}$ Self-instruction, goal setting, self-monitoring, and selfreinforcement are addressed along with specific strategies through a recursive progression of discussion, modeling, memorization, and practice.

\section{SPECIFIC STRATEGY INSTRUCTION}

\section{Text Structure Awareness as a Comprehension Strategy}

Students can learn to attend to the structure of a narrative or expository text and use this to guide their understanding of what they are reading. Having students learn to identify the discourse structure of a text under instructor direction has been shown to improve comprehension. ${ }^{1,2,8}$ Discourse analysis with graphical support helps students identify story grammar components, separate out essential from trivial details, work through the logical relations of a text, and organize and integrate the content into a coherent mental structure. However, there is little guidance on how to move discourse analysis from a teacher-led strategy to a student-regulated strategy.

In a multiple baseline design, Crabtree and colleagues investigated the use of story grammar analysis for three high school students with learning disabilities. ${ }^{27}$ After the students learned how to identify the elements of setting and episode, they stopped at designated points 
in their reading and wrote elements in a structured guide. Using this procedure rather than having the students simply read stories and answer questions about the content improved story recall and comprehension. Maintenance of strategy use consisted only of giving the students the same structured guide but without the prompts of when to stop and use the guide. When asked, students reported they would be likely to use the guide themselves in the future. Such good intentions are not likely to be performed without further support. To make the move to classroom application, SLPs should examine classroom texts, observe lessons, and talk to teachers about opportunities for students to pause in their reading and identify story elements. For story grammar analysis, there is a lot of variety of terms (e.g., the complication may be called a problem, disequilibrium, or initiating event), so it is important that the SLP determine the terminology preferred by the students' teachers.

Expository or informational discourse is more difficult to analyze structurally because of the variety of subgenres and organizations, but evidence suggests benefits, at least from a teacher-led version, here, too. For example, Armbruster et al investigated a discourse structure intervention for fourth- and fifth-grade students. ${ }^{28}$ In a mix of teacher-directed and cooperative group activities, students analyzed social studies textbook passages using causeeffect, problem-solution, and compare-contrast frames. Results showed, compared with a teacher-led content-focused question-answer condition, better recognition and recall of information. Scanlon et al showed similar benefits for middle school students with learning disabilities in inclusive lessons taught by history and civics teachers. ${ }^{29}$

\section{Text Preview and Look-Backs}

For informational discourse, two simple strategies with benefits clear enough that students may incorporate them into their study habits are text preview and look-backs. Both involve teaching students to intentionally become familiar with the text organization of their reading materials and to learn how to locate information. Text preview and look-backs are especially useful for informational texts, where the information may involve a lot of discrete units and the texts vary considerably in organization and reader-friendliness. These strategies can be applied to electronic sources, so that students learn to notice menus and navigational tools and obtain a sense of what the site is about and how to go back to find specific information within it.

Instruction for text preview starts by identifying the type of material (e.g., a book chapter versus a research report) and the student's purpose for reading the material. ${ }^{30}$ The student is guided to travel through the reading to get a sense of the topics covered, the organization, how important points are indicated, and where summaries are located. Chapter titles and section headings show how the material is organized and indicate main ideas of the text that follows. Abstracts, opening paragraphs, and conclusions provide "takeaway" messages. Knowing that there is an index or glossary will be useful later in the reading. SLPs can easily help students become familiar with how informational texts are organized, how to efficiently preview reading materials, and how to match where to look with the purpose for reading.

The companion skill to looking ahead is looking back. Looking back for information involves both awareness that there is a gap in comprehension and an efficient (and permissible) text search procedure. Students rarely search their readings for needed information despite the simplicity and clear helpfulness of this strategy. ${ }^{31-33}$ Garner and colleagues investigated the effects of brief training in using look-backs. ${ }^{33}$ Twenty-four 9- to 13-year-old students, all adequate decoders but poor comprehenders, were randomly assigned to a lookback versus control condition. The control students were taught other comprehension strategies, such as summarization. Five days after training, all the participants were told only, "I am going to ask you to read a short article. You will read it slowly. I will ask you three questions about the article when you're done reading." (33,p.794) To further investigate the students' degree of initiative, one text was laid print-side down and a second was laid print-side up. For the print-side up text, if 
the participant did not look back, the tester cued with, "You can look back at any part of the article to answer the questions." (33,p.794) Results showed that although the two conditions were similar in the mean accuracy of responses for recall-alone questions (31 and 33\%), for responses that benefited from look-backs, the trained participants used them more often (70 versus $22 \%)$ and were correct more often (72 versus $31 \%)$. The trained participants showed a much more active approach to the task, including looking back on their own, flipping the first text over, and asking the investigator if looking back was appropriate. In contrast, all the uses by the control participants occurred in the text-up condition and followed cueing by the investigator.

To teach the look-back strategy, the SLP and students examine the question for whether the answer comes from the students' heads or whether they need to look back in the text to find it. The SLP then models skimming the text to find the most likely section for the information to be located, with comments on why the other sections are not good candidates. ${ }^{17}$ At the relevant section, the SLP notes its potential from the heading and then models slowing down and reading each sentence carefully for the needed information.

It is important that the SLP assures the students that good readers use look-backs, skimming, and text previews as regular parts of strategic reading, because students often get the idea that these are impermissible or undesirable shortcuts. ${ }^{17,33}$ An example that might convince struggling readers is that of Bazerman who interviewed and observed seven physicists as they perused journal articles. ${ }^{34}$ The physicists were asked to talk aloud about their reading process as they read. The scientists considered titles, authors, and abstracts, matching what they read with their research interests and knowledge of the authors' laboratories. They read selectively within the articles, jumping among parts, skimming the text for specific features or surprising elements, and discarding texts that did not stand up to their quick scrutiny. The physicists constantly made judgments about the relative value of a reading versus the time and thought investment.

\section{Learning to Find the Main Idea}

Finding the main idea and constructing summaries of paragraphs, sections, chapters, and articles are central to academic learning. Teaching students to periodically stop and summarize what they have read is one of the most effective ways to improve students' reading comprehension. However, many students need to first learn how to identify a main idea.

There are a variety of effective procedures for teaching how to compose summaries of informational texts, such as gist, rule-governed, and hierarchical. ${ }^{17,30,35}$ Gist summaries involve reading a paragraph one line at a time and gradually composing a single, long sentence that encapsulates the ideas expressed in each line. Rule-governed summaries have systematic procedures for determining topic statements and supporting, redundant, and irrelevant statements, then building these into coherent summaries. Hierarchical summaries make use of the organized structure of expository texts, using chapter, section, and subsection headings to create summaries of large pieces of text.

All these summarization procedures hinge on identifying a main idea, which is difficult for many students. For example, in a multiple baseline design, Wong et al investigated teaching eight seventh graders with learning disabilities to compose well-structured summaries. ${ }^{36}$ The investigators observed that initially, when the students were told to underline and paraphrase the main idea of simple paragraphs, they just repeated random sentences from the paragraphs and became frustrated with their own confusion. As a result, the instruction started with finding main idea statements in simple paragraphs with explicit topic sentences, such as: "Mr. Brown was getting angry. His face was bright red. His pupils seemed to enlarge in size suddenly. His body began to shake. His voice was becoming louder and louder."(36,p.23) A graphical organizer showed the "Mr. Brown" sentence in the center and the details in circles connected by lines to the main idea. To show how the main idea unifies and makes sense of the details, the instructor covered the main idea box and asked the students whether the other sentences made sense without the main idea: "Who are the sentences talking about? Whose voice is getting louder?" The students then 
practiced on paragraphs in which the position of the topic sentence varied, paragraphs with two main ideas, and double paragraphs. Wong et al scaffolded students into paraphrasing main idea statements, adding important detail sentences, and applying their summarization skills to their classroom social studies texts. ${ }^{36}$

Wong et al reported that it took about a month for the students to be able to articulate their thoughts and paraphrase main ideas. ${ }^{36}$ After 3 months of three 30-minute sessions a week, there was noticeable improvement on summarization elements and recall of social studies passages. Six of the students maintained use 1 month after the end of instruction and showed substantial transfer to general science texts. However, there was considerable varia- tion in achievement. Two students quickly learned how to summarize and apply the selfquestioning procedure to their reading. Those students maintained use and made modifications that indicated ownership of the strategy. Two students showed little motivation, slow learning, and lack of retention. Wong et al noted that these students showed a fundamental disengagement with academic learning that extended beyond the study. ${ }^{36}$

The foregoing instruction involved paragraphs with explicit main idea statements. Students must also deal with paragraphs that lack topic sentences or have trivial, redundant, or irrelevant details. A graphical organizer can be used to reveal an unstated main idea (Fig. 1). The detail sentences are placed in isolated

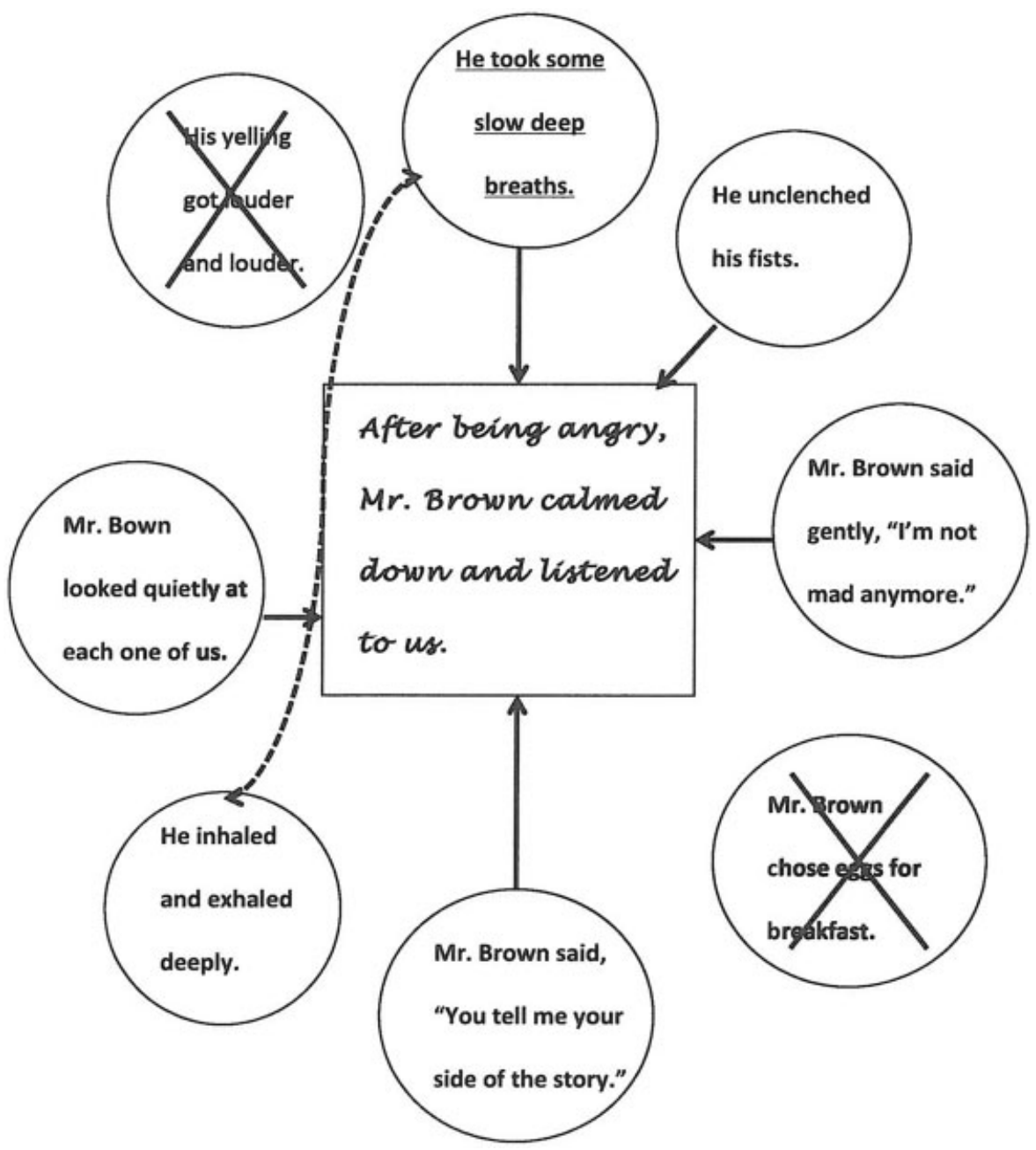

Figure 1 Graphical organizer for implicit main ideas and irrelevant or redundant details. 
circles around an empty main idea box. Each sentence is then examined for how it relates to the others. When an idea that is common to several detail sentences is determined, that idea is written in the main idea box and linking lines are drawn to those detail circles. Irrelevant detail circles are crossed off. Important detail sentences are underlined. One of each pair of redundant details is underlined. Each relevant detail sentence is then reviewed to confirm that the initial main idea inference is supported by all the details.

Summarization can operate on noncontinuous document text as well as on prose text. Students need to be able to extract the main idea from images, headings, bulleted lists, and isolated statements in the multimodal texts involved in specialized subject areas, such as science. ${ }^{6}$ Shanahan and Shanahan describe an example for chemistry in which, instead of summarizing in a main idea and detail format, students fill in a chart of substances, properties, and reactions as they read. ${ }^{37}$ For math, Shanahan and Shanahan suggest a chart listing one column as the "big idea," the next as the formal definition, followed by the formula, and then an example. History is suited to a summarization chart of who, what, where, when, how, and why for each event along with a specification of the relationship between events (which is more important than the event features or chronological succession). SLPs can collaborate with subject area teachers to identify graphical supports that match each features of each discipline. Procedures for teaching customized strategies and disciplinary literacy are only emerging, but they are needed for secondary students to attain advanced levels of text comprehension.

\section{SOME CONSIDERATIONS IN COMPREHENSION INTERVENTION}

\section{Text Choices for Comprehension Intervention}

Kamil et al emphasize careful text selection to ensure that the text matches the strategy being learned. ${ }^{2}$ A narrative text is more amenable to a strategy of identifying the characters or the problem than identifying the main idea of the paragraphs. Informational texts are suitable to a main idea strategy, but instruction should start with paragraphs that contain explicit topic statements and details that all support the topic statement. The end point of strategy use is independent application to classroom readings, but the SLP needs to initially provide repeated opportunities with simple, structured texts.

Sets of passages from instructional programs provide repeated, equivalent opportunities for learning and practice. A reading fluency program called QuickReads provides sets of controlled difficulty passages on a single topic within the subject areas of history, civics, and science at second- to fourth-grade reading levels. ${ }^{38}$ These passages are simple enough to avoid decoding issues for older students, but challenging enough for learning how to identify main ideas or summarize. The SLP could modify the passages to provide confusing or missing elements for monitoring and clarification strategies. Making comprehension monitoring a detective game of spotting problems in texts can increase student motivation and attention to detail. ${ }^{39}$ Activities that involve carrying out what is read motivate students to read carefully. For example, 202 Oozing, Bubbling, Dripping, and Bouncing Experiments contains short, simple science activities that provide multiple opportunities to monitor and clarify comprehension. ${ }^{40}$

Short passages taken from social studies and science texts or source papers for classroom projects can be used for learning and practice, although the focus when the student is with the SLP should be on strategies, not on getting an assignment done. Trade books, magazines, and Web sites can be selected to match classroom topics or individual student interests. A Web site that reviews mountain bikes or video games is a motivating context in which to apply text strategies. These sources are typically visually busy sites, with pictures, subheadings, bulleted lists, points to ponder, and salient facts. Students need to learn how to sort through and make sense of these discrete information bites just as they do with prose texts.

For classroom instruction, the text selection should match to the reading level of the student. ${ }^{2}$ These text choices are challenging enough to require strategies but not so difficult 
that the student struggles with basic comprehension. However, students who cannot read at grade level must still find a way to learn the curricular content. SLPs can use these toodifficult texts but scaffold comprehension through shared reading and spoken interactions around the printed text. By encouraging survival strategies like text preview and look-backs, students can often manage these challenging texts. Having multiple copies of the text, enlarging text on a computer monitor, and sitting on the same side of the table with a student all help share the visual information for reading and strategy practice. Underlining and marginalia can help the student focus on the important parts of the text.

\section{Being Strategic about Strategy Intervention}

Older students can learn reading strategies and make sizeable gains in reading comprehension with intensive, explicit, individualized instruction for struggling readers by trained professionals. ${ }^{2}$ For example, Vaughn et al provided yearlong daily, small-group comprehensive reading intervention to eighth graders who had shown poor response to intervention the prior year. ${ }^{41}$ The comprehension instruction included teaching and scaffolding student use of preview, prediction, summarization, selfmonitoring, and repair on narrative and expository texts. Results showed large significant effects on a standardized measure of comprehension compared with a no-treatment comparison condition.

SLPs are well situated to provide the comprehension strategy part of reading intervention. However, to be effective, SLPs need to be strategic about their strategy instruction. In the primary grades, SLPs may use summarization, question generation, discourse analysis, and graphical organizers as intervention procedures to improve language skills. However, in the later grades, the focus should be on students taking on strategies as their own learning tools.

For student ownership, an SLP should choose a few simple strategies that have obvious benefits and that can be easily learned and used. The SLP can observe students, examine work artifacts, and collaborate with teachers to iden- tify strategies that make sense within content lessons. Classroom observation can reveal both explicit and indirect ways teachers model and support strategy use. The SLP can provide learning and practice experiences within structured activities separate from the classroom lessons. After students gain some facility applying strategy to short, well-structured texts, they can move into passages with more varied structure excerpted from classroom texts. The focus should continue to be on strategy use without the pressure to demonstrate mastery of new curricular material. When students can manage this with minimal support, strategy use can move into content-learning situations. A sheltered experience might be with a resource teacher working with the student on a classroom lesson. Collaborations can then move to subject area teachers. Over repeated opportunities with reminders in advance and checkups during reading, students will develop the habits of mindful reading: asking themselves questions, monitoring their comprehension, and summarizing what they have read.

SLPs should teach reading comprehension strategies through cognitive modeling. To be an effective cognitive model, the clinician reviews the reading selection in advance, considering the text from a student perspective and checking that it matches the target strategies. Points in the text are planned to model particular strategies (e.g., "This paragraph isn't clear, I will reread it and find the main idea."), demonstrating how to read and think about reading at the same time. Cognitive modeling should be applied not only to preplanned texts but also to more natural situations where students are likely to encounter bumps in the application process.

For strategy instruction, it is particularly important that treatment goals and progress data examine the process as well as the product of comprehension. There are many reasons a student might improve on the number of correct responses on a reading. The student may have gained further knowledge of the topic through other means such as a teacher explanation or a class video. The student may even have rejected the SLP's targeted strategy but may have gained greater general awareness that has led to a different comprehension strategy. The 
SLP should seek evidence that the student is using the strategies taught by the SLP or developed other, possibly better solutions. Such process data come from observing a student's actions during reading, having the student stop and say what he or she is thinking (called think-alouds), having the student say or show what he or she did after reading, and recording the level of prompting required by the SLP. ${ }^{42}$ To reveal performance beyond the speech room, the SLP can observe in the classroom, have the teacher embed a strategy question in a class lesson, or have the student talk about an assignment. These assessment procedures can reveal not only how independent and dependable the student is in his or her strategy use but also where breakdowns in text comprehension are occurring.

Finally, SLPs need to stay therapeutic. Almost any academic activity will provide rich language and learning opportunities, but only a small number of goals can be addressed effectively given the limited contact time of speechlanguage services. Students need repeated opportunities, intensity, systematic scaffolding, and explicit instruction (RISE) to make changes. ${ }^{15,41}$ SLPs should choose a small number of goals for which they have the time and resources to provide sufficient RISE to obtain noticeable, functional change and help students become more competent and independent learners.

\section{Student Engagement in Strategy Learning}

Finally, buy-in is critical for adolescents to take on the habits of strategic reading. In instructional programs where students are motivated to learn, there is a cascading and reciprocal positive effect between student interest and educational achievement. Guthrie et al found that even low-achieving students do better and have positive attitudes toward challenging learning tasks when they have confidence in their capacity, interest in the topic, and the tools for success, such as strategy instruction and relevant, accessible texts. ${ }^{43}$

Teachers may use external incentives and reminders of the impact of learning on grades, but research suggests that these types of moti- vators have a detrimental effect on student engagement and learning outcomes. ${ }^{2}$ When working hard and good grades are emphasized, levels of text recall and reading comprehension are lower than when the focus is on how much information students can remember and understand and they are left to decide the effort necessary. ${ }^{44,45}$ In addition, students show better learning when errors are treated as growth opportunities instead of failure and when feedback is informational but not controlling.

Stimulating situational interest may be particularly important for boys who are less successful than girls in academic topics that do not interest them. ${ }^{39,46}$ For example, Oakhill and Petrides compared fifth-grade boys and girls on passages they had rated as higher and lower interest: the boys preferred a piece on spiders, and the girls preferred a piece about children being evacuated during war. The boys were $60 \%$ correct on the high-interest passage questions and $38 \%$ for the low-interest ones. In contrast, the girls performed at $\sim 62 \%$ for both high- and low-interest passages. ${ }^{39}$

For effective strategy instruction, older students need to see that the efforts they make will result in noticeable improvements in their academic lives. They should have some say in their course of treatment, such as identifying learning goals, selecting instructional topics and materials, and determining outcome measures. The SLP needs to go beyond structured practice time to working with the older student right into the classroom, identifying obstacles and celebrating successes toward becoming a more independent, strategic reader.

\section{CONCLUSION}

Academic reading and listening comprehension involve active, mindful engagement with meaningful texts. The strategies occur before reading, such as previewing subheadings and looking for organizing concepts; during reading, such as identifying the main idea and rereading for clarification; and after reading, such as reflecting on what has been learned and looking back for gaps in knowledge. Poor readers need to be explicitly taught strategies and supported toward independent, habitual use to improve academic text comprehension. Systematic 
procedures, cognitive modeling, and connections with the classroom support older students becoming engaged learners who can apply comprehension strategies to achieve educational success.

\section{REFERENCES}

1. National Reading Panel. Teaching Children to Read: An Evidence-Based Assessment of the Scientific Research Literature on Reading and Its Implications for Reading Instruction (NIH Publication 00-4769). Washington, DC: U.S. Department of Health and Human Services, National Institute of Child Health and Human Development; 2000

2. Kamil ML, Borman GD, Dole J, Kral CC, Salinger $\mathrm{T}$, Torgesen J. Improving Adolescent Literacy: Effective Classroom and Intervention Practices: A Practice Guide (NCEE \#2008-4027). Washington, DC: Institute of Education Sciences, U.S. Department of Education; 2008

3. Ukrainetz TA, Fresquez EF. "What isn't language?": a qualitative study of the role of the school speech-language pathologist Lang Speech Hear Serv Sch 2003;34:284-298

4. Merriam-Webster. Merriam-Webster's Collegiate Dictionary, 10th ed. Springfield, MA: Author; 1993

5. Kutner M, Greenberg E, Baer J. National Assessment of Adult Literacy (NCES 2006-470). Washington, DC: National Center for Education Statistics; 2006

6. Alvermann DE, Wilson AA. Comprehension strategy instruction for multimodal texts in science. Theory Pract 2011;50:116-124

7. RAND Reading Study GroupReading for Understanding: Toward a Research and Development Program in Reading Comprehension. Santa Monica, CA: RAND; 2002

8. Gersten R, Fuchs LS, Williams JP, Baker S. Teaching reading comprehension strategies to students with learning disabilities: a review of research. Rev Educ Res 2001;71:279-320

9. Rosenshine B, Meister C. Reciprocal teaching: a review of the research. Rev Educ Res 1994; 64:479-530

10. Rosenshine B, Meister C, Chapman S. Teaching students to generate questions: a review of the intervention studies. Rev Educ Res 1996; 66:181-221

11. Solis M, Ciullo S, Vaughn S, Pyle N, Hassaram B, Leroux A. Reading comprehension interventions for middle school students with learning disabilities: a synthesis of 30 years of research. J Learn Disabil 2012;45(4):327-340
12. Swanson E, Hairrell A, Kent S, Ciullo S, Wanzek JA, Vaughn S. A synthesis and meta-analysis of reading interventions using social studies content for students with learning disabilities. J Learn Disabil 2014;47(2):178-195

13. Paris SG, Wasik BA, Turner JC. The developmental of strategic readers. In: Barr R, Kamil ML, Mosenthal PB, Pearson PD, eds. Handbook of Reading Research, Vol. II. New York, NY: Longman; 1991:609-640

14. Leontiev AN. The problem of activity in psychology. In Wertsch JV, ed. The Concept of Activity in Soviet Psychology. New York: M.E. Sharpe; 1981: $37-71$

15. Ukrainetz TA. Assessment and intervention within a contextualized skill framework. In: Ukrainetz TA, ed. Contextualized Language Intervention. Austin, TX: Pro-Ed; 2006:59-94

16. Mason LH. Explicit self-regulated strategy development versus reciprocal questioning: effects on expository reading comprehension among struggling readers. J Educ Psychol 2004;96:283-296

17. Swanson PN, de la Paz S. Teaching effective comprehension strategies for students with learning and reading disabilities. Interv $\mathrm{Sch} \mathrm{Cl}$ 1998; 33:209-218

18. Swanson HL, Hoskyn M. Experimental intervention research on students with learning disabilities: a meta-analysis of treatment outcomes. Rev Educ Res 1998;68:277-321

19. Pearson PD, Fielding L. Comprehension instruction. In: Barr R, Kamil ML, Mosenthal PB, Pearson PD, eds. Handbook of Reading Research, Vol. II. New York, NY: Longman; 1991:815-860

20. Baker S, Gersten R, Scanlon D. Procedural facilitators and cognitive strategies. Learn Disabil Res Pract 2002;17:65-77

21. McKeown MG, Beck IL, Blake RGK. Rethinking reading comprehension instruction: a comparison of instruction for strategies and content approaches. Read Res Q 2009;44:218-253

22. Palincsar AS, Brown AL. Reciprocal teaching of comprehension-fostering and comprehensionmonitoring activities. Cogn Instr 1984;1:117-175

23. Shanahan T, Callison K, Carriere C, et al. Improving Reading Comprehension in Kindergarten through 3rd Grade: A Practice Guide (NCEE 2010-4038). Washington, DC: Institute of Education Sciences, U.S. Department of Education; 2010

24. Chan LKS, Cole PG. The effects of comprehension monitoring training on the reading competence of learning disabled and regular class students. Remedial Spec Educ 1986;7:33-40

25. Mason LH, Meadan H, Hedin L, Corso L. Selfregulated strategy development instruction for expository text comprehension. Teach Except Child 2006;38:47-52 
26. Graham S, Harris KR. Assessment and intervention in overcoming writing difficulties: an illustration from the self-regulated strategy development model. Lang Speech Hear Serv Sch 1999; 30:255-264

27. Crabtree T, Alber-Morgan SR, Konrad M. The effects of self-monitoring of story elements on the reading comprehension of high school seniors with learning disabilities. Educ Treat Child 2010; 22:187-203

28. Armbruster BB, Anderson TH, Meyer JL. Improving content-area reading using instructional graphics. Read Res Q 1991;26:393-416

29. Scanlon D, Deshler DD, Schumaker JB. Can a strategy be taught and learned in secondary inclusive classrooms? Learn Disabil Res Pract 1996; 11:41-57

30. Ukrainetz TA, Ross CL. Text comprehension: facilitating active and strategic engagement. In: Ukrainetz TA, ed. Contextualized Language Intervention: Scaffolding Prek-12 Literacy Achievement. Austin, TX: Pro-Ed; 2006:503-564

31. August DL, Flavell JH, Clift R. Comparison of comprehension monitoring of skilled and less skilled readers. Read Res Q 1984;20:39-53

32. Garner R, Reis R. Monitoring and resolving comprehension obstacles: an investigation of spontaneous text lookbacks among upper-grade good and poor readers' comprehension. Read Res Q 1981; 16:569-582

33. Garner R, Hare VC, Alexander P, Haynes J, Winograd P. Inducing use of a text lookback strategy among unsuccessful readers. Am Educ Res J 1984;21:789-798

34. Bazerman C. Physicists reading physics. Writ Commun 1985;2:3-23

35. Been TW, Steenwyk FL. The effect of three forms of summarization instruction on sixth graders' summary writing and comprehension. J Read Behav 1984;16:297-306
36. Wong BYL, Wong R, Perry N, Sawatsky D. The efficacy of a self-questioning summarization strategy for use by underachievers and learning disabled adolescents in social studies. Learn Disabil Focus 1986;2:20-35

37. Shanahan T, Shanahan C. Teaching disciplinary literacy to adolescents: rethinking content-area literacy. Harv Educ Rev 2008;78:40-59

38. Hiebert EH. QuickReads: A Research-Based Fluency Program. Parsippany, NJ: Pearson; 2003

39. Oakhill JV, Petrides A. Sex differences in the effects of interest on boys' and girls' reading comprehension. Br J Psychol 2007;98(Pt 2): 223-235

40. Van Cleave J. 202 Oozing, Bubbling, Dripping, and Bouncing Experiments. New York, NY: Wiley; 1996

41. Vaughn S, Wexler J, Leroux A, et al. Effects of intensive reading intervention for eighthgrade students with persistently inadequate response to intervention. J Learn Disabil 2012; 45(6):515-525

42. Laing Gillam S, Fargo JD, St Clair Robertson K. Comprehension of expository text: insights gained from think-aloud data. Am J Speech Lang Pathol 2009;18(1):82-94

43. Guthrie JT, Klauda SL, Ho AN. Modeling the relationships among reading instruction, motivation, engagement, and achievement for adolescents. Read Res Q 2013;48:9-26

44. Graham S, Golan S. Motivational influences on cognition: task involvement, ego involvement, and depth of information processing. J Educ Psychol 1991;83:187-194

45. Grolnick WS, Ryan RM. Autonomy in children's learning: an experimental and individual difference investigation. J Pers Soc Psychol 1987;52(5):890-898

46. Ainley M, Hillman K, Hidi S. Gender and interest processes in response to literary texts: situational and individual interest. Learn Instr 2002;12:411-428 